\title{
APPLYING A FUZZY SET QUALITATIVE COMPARATIVE ANALYSIS FOR CONFLICT RESOLUTION DURING NEW SERVICE DEVELOPMENT
}

\author{
Kalliopi Chatzipanagiotou, Glasgow University, UK, k.chatzipanagiotou@glasgow.ac.uk \\ Spiros Gounaris, Strathclyde University, UK, spiros.gounaris@ strath.ac.uk \\ Achilleas Boukis, Sussex University, UK, a.boukis@ sussex.ac.uk \\ Helen Perks, Nottingham University, UK, helen.perks@nottingham.ac.uk
}

\begin{abstract}
The management of the New Service Development (NSD) process remains a key research priority for service organizations. As a diverse mix of team members with different skills, perspectives and backgrounds participate in development teams and close collaboration is required among them, conflicts are likely to arise among team members. Different team members perceive conflict episodes in a different way and often embrace different conflict management behaviours and orientations (e.g. competing, avoiding) to deal with them. This study recognises NSD team as a complex system, through which individual members' conflict management style choices enable team developmental dynamics, which sequentially lead to intragroup conflict resolution. Although a lot of work exists around the role of individual members' conflict management styles, little research scrutiny is attracted on how teams solve intragroup conflicts and even limited empirical evidence is available regarding the linkages between individual and team factors can contribute to resolve intragroup conflicts. The present study taking under consideration the causal complexity, asymmetry and idiosyncratic nature of NSD conflict resolution, utilizes Complexity theory and leverages the advantages of fs/QCA in order to shed light on the NSD intragroup conflict resolution. Data was collected from employees in several service industries such as advertising, financial, insurance, consulting, IT services and telecommunications providers. The results confirm the major tenets of Complexity theory highlighting that any attempt to examine complex phenomena, such as NSD conflict resolution, as simple ones, based on symmetrical methodological approaches, may lead to simplistic and distorted explanations. In fact, the results demonstrate that there is not a 'one fits all' solution in order to solve NSD conflicts. Different facets for both the conflict-management styles and team dynamics act in various combinations in order to predict high scores in NSD conflict resolution.
\end{abstract}

